\title{
PHENOLIC COMPOUNDS IN NATURAL SOLUTIONS OF A CONIFEROUS FOREST ${ }^{1}$
}

\author{
CHRISTIANE GALLET ${ }^{2,3, *}$ and FRANÇOIS PELLISSIER ${ }^{2}$ \\ 'Departmem of Life Sciences, Laboratory of Atritude Ecosystems Dynamics \\ F-73376 Lo' Bourget-du-lac Cedex, France \\ ${ }^{3}$ Swiss Federal Insitute of Technology \\ IATE-Pédologic \\ 1015 Lausanne, Switzerland
}

(Received January 2, 1997; accepted June 15, 1997)

\begin{abstract}
Phenolic compounds have been identified previously as potentially responsible for allelopathic interferences in spruce forest at high altitude. They have now been analyzed in canopy leachates, snow, and soil solutions collected from the three layers of the podsolic soil: OA. E. and B. Leachates were characterized by high tanning capacity and by $p$-hydroxyacetophenone (found at $10^{6} \mathrm{M}$ ) atso detected as the major $\left(10^{7} \mathrm{M}\right.$ ) monomeric compound in snow. At least 10 phenolic monomers, including vanillic, $p$-hydroxybenzoic, and protocatechuic acids were identified in capillary waters extracted from the $O A$ layer with their sum reaching $2 \times 10^{6} \mathrm{M}$. These monomers were only a small pan ( $1 \%)$ of the total phenolics, In soil solutions, significant decreases in phenolic concentrations with depth were observed between the E and $B$ layers, with qualitative modifications of the phenolic pattem. Spruce leachates and soil solutions exhibited high temporal variability, resulting in transitory allelopathic potential towards both aerial and subterranean parts of spruce seedlings. The occurrence of various and soluble phenolic coumpounds in the whole forest system, including $p$-hydroxyacetophenone, which persist from green needles to soil solutions, suggests that they could be involved in complex and interactive processes occurring during organic matter accumulation on the coniferous forest floor.
\end{abstract}

Key Words-Coniferous forest, leachates, snow, soil solutions, allelopathy. tanning activity, phenolic acids, $p$-hydroxyacetophenone, Picea abies.

*To whom correspondence should be addressed.

${ }^{2}$ Part of these results were presented during the 15th International Conference on Plant Growth Substances, July 14-18, 1995, Minneapolis, Minnesota. 


\section{INTRODUCTION}

There is growing evidence that phenolic compounds play a central role in controlling litter degradation rates and nutrient cycling processes in forest systems (Sugai and Schimel, 1993; Northrup et al., 1995). Direct toxicity of some of these molecules on tree seed germination (Odén et al., 1992; Pellissier, 1993), tree seedlings (Kil and Yim, 1983; Inderjit and Mallik, 1996), and microorganism growth (Field and Lettinga, 1992) is also now well documented, mostly from greenhouse experiments. The establishment of such interactions, also called allelopathy, has led to numerous identifications of phenolic compounds in plant materials (fresh or decaying leaves, roots, shoots, buds, flowers, etc.) and in the soil organic layers. Quantification procedures of these compounds have principally involved soil samples collected on the field and analysis by water leaching and extraction (Whitehead et al., 1983) or more drastic procedures using complexants such as sodium pyrophosphate (Vance et al., 1985) or organic solvents (Dalton et al., 1987). The major conclusion of these studies was that the quantitative results vary mainly with the method of analysis. Thus, controversy on the reality in the field of such chemical inhibitions has increased essentially because of the difficulties involved in measuring the amounts of allelochemicals really available to living organisms.

On the other hand, our knowledge of the transport and of the extracellular stability of such secondary metabolites in natural solutions is incomplete. However, leachates and throughfalls, especially in coniferous forests, are known to provide nonnegligible inputs of inorganic and organic compounds to the soil following interception of rainwater by canopy (or understorey) species (Parker, 1983; Arthur and Fahey, 1993). Furthermore, soil solutions contain various organic acids (including phenolic compounds) with chelating properties towards aluminum and iron, which play important roles in pedogenetic processes like podzolization (Vance et al., 1986, Pohlman and McColl, 1988). All these solutions could be suspected to be active in allelopathic processes, because of their strong ability to carry soluble molecules from the donor plant to the root system of the target plant.

The objective of this study was to verify if the potential allelochemicals (principally phenolic acids) previously isolated in plant, litter, and humus materials of high-altitude spruce (Picea abies L. Karsten) forest (Gallet and Lebreton, 1995) were recovered in detectable amounts in natural solutions in the vicinity of spruce seedlings, potentially sensitive to such metabolites. Among these compounds, $p$-hydroxyacetophenone represents an efficient marker of spruce metabolism, because of its abundance and specificity. The solutions studied included: throughfalls and snow, which could reach the aerial part of the target plant, and soil solutions in close contact with the root system, i.e., capillary waters (Zabowski and Ugolini, 1990). 


\section{METHODS AND MATERIALS}

Study Site. Sampling in 1993 was at $1860 \mathrm{~m}$ in a bilberry-spruce forest (530 trees/ha) in Tarentaise (northern Alps, Savoie, France) on a humoferric podzol, characterized by poor spruce regeneration on decaying stumps (Bernier et al., 1993). The understorey was dominated by crowded bilberry (Vacinium myrillus L.) areas, with litterfalls of $360 \mathrm{~kg}$ dry wt $/$ ha/ $/ \mathrm{yr}$. The mixed litter ( 3 $\mathrm{cm}$ thick) was spruce needles (litterfalls $=650 \mathrm{~kg} \mathrm{dry} w \mathrm{t} / \mathrm{ha} / \mathrm{yr}$ ), bilberry leaves, and moss fragments on a mor humus $\mathrm{OA}\left(\mathrm{H}_{2} \mathrm{O} \mathrm{pH}=3.8, \mathrm{C}-\right.$ to- $\mathrm{N}$ ratio $\left.=65\right)$. Thicknesses of the three layers of the humoferric podzol, OA, E, B (AFES, 1992), were 8,20 , and $25 \mathrm{~cm}$, respectively, with weakly pronounced transitions.

Throughfalls and Snow Sampling. Throughfalls were collected during September and October with PVC gutters and glass funnels under three different adult trees, as previously described (Gallet, 1994). Throughfalls were protected from litter contact by a 2-mm PVC mesh. Incident rain (as control) was collected with the same apparatus at a single site in a natural clearing. The samples were brought back to the laboratory as soon as possible after rain, and immediately analyzed.

Triplicate snow samples were collected in under spruce during May, allowing potential leaching by melting snow of fallen stems and needles. Control snow was also collected at a single site in a clearing, where there were no influences of tree fallouts. The snow layer was divided into three 5-cm-high slices in spruce sites (e.g., surface, medium, and basic) and into two $10-\mathrm{cm}$ high slices in the control site (e.g., surface and basal). Volumes cquivalent to 1 liter of water were stored in polyethylene bags and immediately analyzed after melting at room temperature and filtering.

Extraction of Soil Solutions. Many methods used to obtain soil solutions cause modifications of the chemical content. In this study, soil centrifugation was selected because of the negligible impact on the organic content of the capillary waters (Giesler and Lundstrom, 1993; Keller, 1995). Soil samples were collected from July through October after three significant rains had caused leaching down to the B layer. Once drainage was finished, soils were sampled with an auger. Because a minimum volume of $300 \mathrm{ml}$ of soil solutions was found to be necessary for phenolic monomer extraction, the fresh weight of soil extracted was ca. $1 \mathrm{~kg}$ for the OA horizon, and ca. $2 \mathrm{~kg}$ for the $\mathrm{E}$ and B horizons. At least five different samples were bulked into a single sample for each horizon. After storage at $-18^{\circ} \mathrm{C}$ and then thawing, soil samples were centrifuged at $3400 \mathrm{~g}$ (Sorvall RC apparatus, HS4 rotor, and swinging buckets) at $4{ }^{\circ} \mathrm{C}$ for 90 min (Keller, 1995). Centrifuged solutions were drawn from the collection cup with a pipet and bulked until $300 \mathrm{ml}$ was obtained. The whole was then filtered.

Chemical Analysis. Dissolved organic carbon (DOC) was analyzed by IR detection, Shimadzu 500) and pH was measured on one aliquot of each solution. 
Total phenols were determined with Folin-Ciocalteu reagent using gallic acid as a standard (Marigo, 1973). Tanning capacity was determined by the colorimetric method of Bate-Smith, modified by Schultz et al. (1981), with tannic acid as a standard. Monomeric compounds (phenolic acids sensu lato) were extracted from acidified solutions (by $2 \mathrm{~N} \mathrm{HCl}$ ) with ethyl ether and redissolved in ethanol before HPLC analysis as described earlier (Gallet, 1994).

Statistical Analysis. Matched data were compared using Wilcoxon signedranks test for dependant variables (for $N=3, P$ associated can not go below 0.125 ), and means were compared using the Mann-Whitney $U$ test. Proportions were compared using the binomial test.

\section{RESULTS}

The brown-orange coloration of the spruce throughfalls, compared with the colorless incident rain sampled in the clearing gave evidence of great chemical changes, confirmed by the phenolics analysis (Table 1). The $\mathrm{pH}$ of the spruce leachates was significantly lower than that of the incident rain and the total phenolic content had increased by about 50 -fold. Total phenolic compounds included mostly polymerized compounds, as revealed by the high tanning capacity compared with the low amounts of phenolic monomers detected by HPLC analysis. Amounts of $p$-hydroxyacetophenone reached a mean value close to $10^{-6} \mathrm{M}$ (or $0.11 \mathrm{mg} /$ liter, e.g., $0.4 \%$ of total phenols). Under the spruce canopy, comparisons between the two sampling dates gave relevant differences in total phenols and $p$-hydroxyacetophenone content.

Snow samples collected under spruce trees exhibited a few more total phenols than samples of the control site (Table 2). In spruce stands, surface slices $(10-15 \mathrm{~cm})$ contained significantly more total phenols compared to medium slices $(5-10 \mathrm{~cm})$. Differences between surface slices and basal slices $(0-5 \mathrm{~cm})$ were not significant, probably because of the very high variability of the latter. $p$-Hydroxyacetophenone was the only compound present in snow in detectable amounts, with higher concentrations in surface slices.

Organic analysis of capillary waters of the three layers of the podzolic soil (Table 3) revealed no differences in $\mathrm{pH}$ and total phenol amounts. More visible modifications occurred when reaching the $\mathrm{B}$ layer: the $\mathrm{pH}$ became less acidic, and the total phenolics were reduced to approximately half of those in the $E$ layer. Phenolic carbon, estimated by Folin-Ciocalteu method, accounted only for about $10 \%$ of DOC, and without significant correlation between DOC and total phenols (in milligrams per liter) $(r=0.33)$. Temporal variability was significant, with far higher concentrations in total phenols observed for the first sampling date compared with the two others (Wilcoxon matched sign test, $N=$ $3, P=0.125$ ). Monomeric analysis (Table 4) showed the same trend, i.e., 


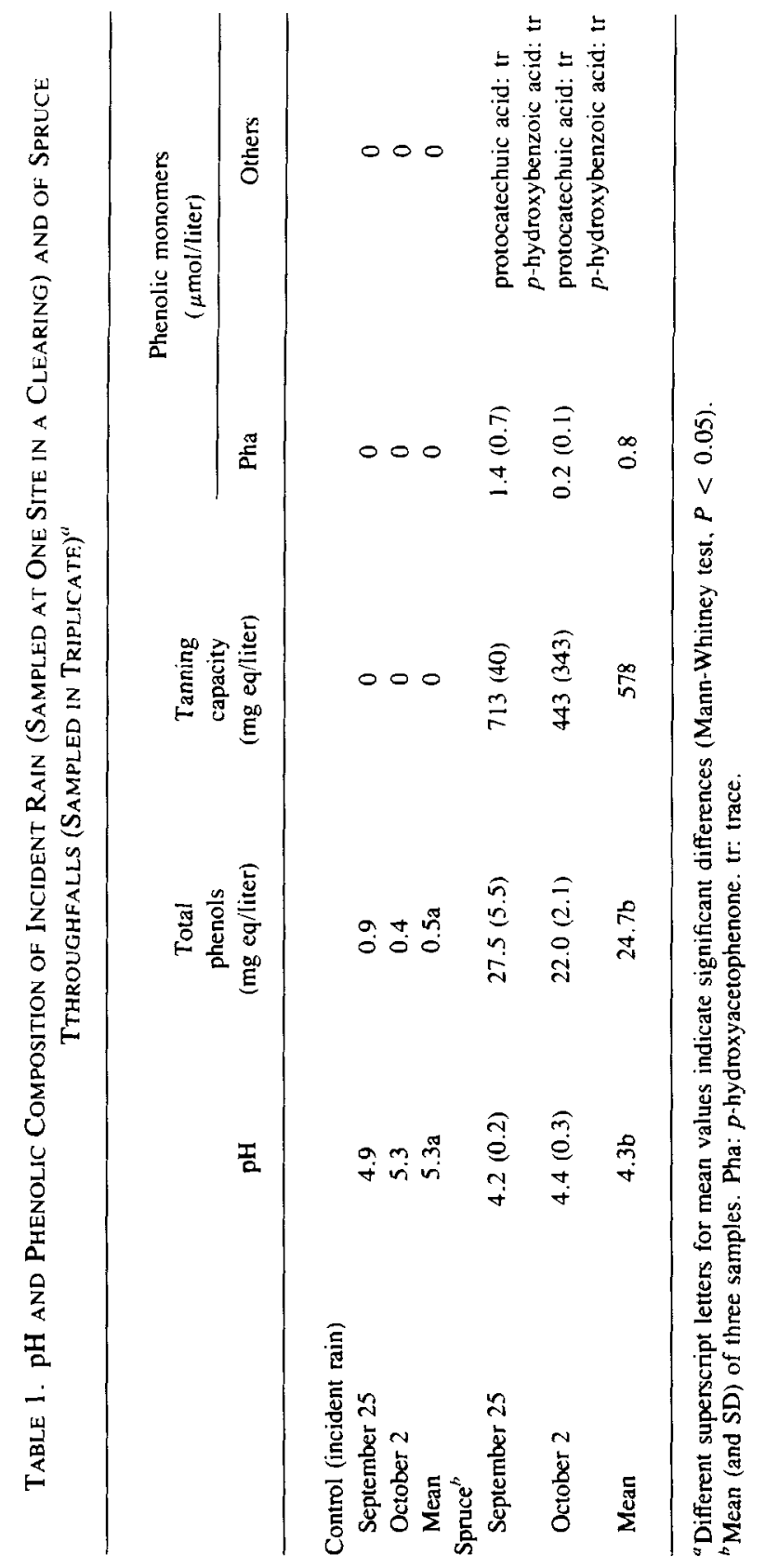


Table 2. Phenolic Composition of Snow Samplid by Slichs on the Ground at a Clearing (Onf Replicate) and of Spruce Forest (Three: Replicateis) During $\mathrm{MAY}^{a}$

\begin{tabular}{|c|c|c|c|c|}
\hline & $\mathrm{pH}$ & $\begin{array}{c}\text { Total } \\
\text { phenols } \\
\text { (mg eq/liter) }\end{array}$ & $\begin{array}{c}\text { Tanning } \\
\text { capacity } \\
\text { (mg eq/liter) }\end{array}$ & $\begin{array}{c}\text { Pha } \\
\text { ( } \mu \mathrm{mol} / \mathrm{liter})\end{array}$ \\
\hline \multicolumn{5}{|l|}{ Control } \\
\hline $10-20 \mathrm{~cm}$ & 5.6 & 0.68 & 0 & 0 \\
\hline $0-10 \mathrm{~cm}$ & 5.4 & 1.42 & 0 & 0 \\
\hline \multicolumn{5}{|l|}{ Spruce" } \\
\hline $10-15 \mathrm{~cm}$ & $5.6(0.2)$ & $2.30(1.43)$ & 0 & 0.2 \\
\hline $5-10 \mathrm{~cm}$ & $5.5(0.1)$ & $1.01(0.32)$ & 0 & 0.05 \\
\hline $0-5 \mathrm{~cm}$ & $5.4(0.1)$ & $3.33(2.51)$ & 0 & tr \\
\hline
\end{tabular}

"Thickness is given from the ground. Pha: p-hydroxyacetophenone.

"Mean (and SD) of three samples. For HPLC quantification, the three replicates were bulked before analysis.

Table 3. pH, DOC, and Total Phtnol Contents of Capillary Water Collected in Thrfe Layizs of Podzolic Soll Under Spruce Covfr ${ }^{\prime}$

\begin{tabular}{|c|c|c|c|c|}
\hline & \multirow[b]{2}{*}{$\mathrm{pH}$} & \multirow{2}{*}{$\begin{array}{c}\text { DOC } \\
\text { (mg/liter) }\end{array}$} & \multicolumn{2}{|c|}{ Total phenols } \\
\hline & & & mg eq/liter & $\%$ of DOC \\
\hline \multicolumn{5}{|l|}{ OA layer } \\
\hline July 5 & 3.5 & 330 & 39.8 & 18 \\
\hline July 13 & 3.9 & 480 & 29.6 & 6 \\
\hline October 13 & 3.5 & 570 & 21.7 & 3 \\
\hline Mean & $3.6 \mathrm{a}$ & $460 a$ & $30.4 a$ & $8 a$ \\
\hline \multicolumn{5}{|l|}{ E layer } \\
\hline July 5 & 3.6 & 450 & 65.9 & 16 \\
\hline July 13 & 3.4 & 360 & 18.1 & 7 \\
\hline October 13 & 3.7 & 318 & 16.4 & 8 \\
\hline Mean & $3.6 a b$ & $376 a$ & $33.5 \mathrm{a}$ & $11 a b$ \\
\hline \multicolumn{5}{|l|}{ B layer } \\
\hline July 5 & 4 & 360 & 30.9 & 12 \\
\hline July 13 & 3.9 & 390 & 9.9 & 3 \\
\hline October 13 & 4.3 & 210 & 10.0 & 11 \\
\hline Mean & $4.1 \mathrm{ac}$ & 320 i & $16.9 \mathrm{~b}$ & $8 a c$ \\
\hline
\end{tabular}

"Total phenols are expressed in milligrams of gallic acid equivalent per liter and as percentage of DOC (with $49.4 \%$ of $\mathrm{C}$ in gallic acid). Different superscript letters for mean values indicate significant differences (Wilcoxon signed-rank test, $P<0.125$ ). 


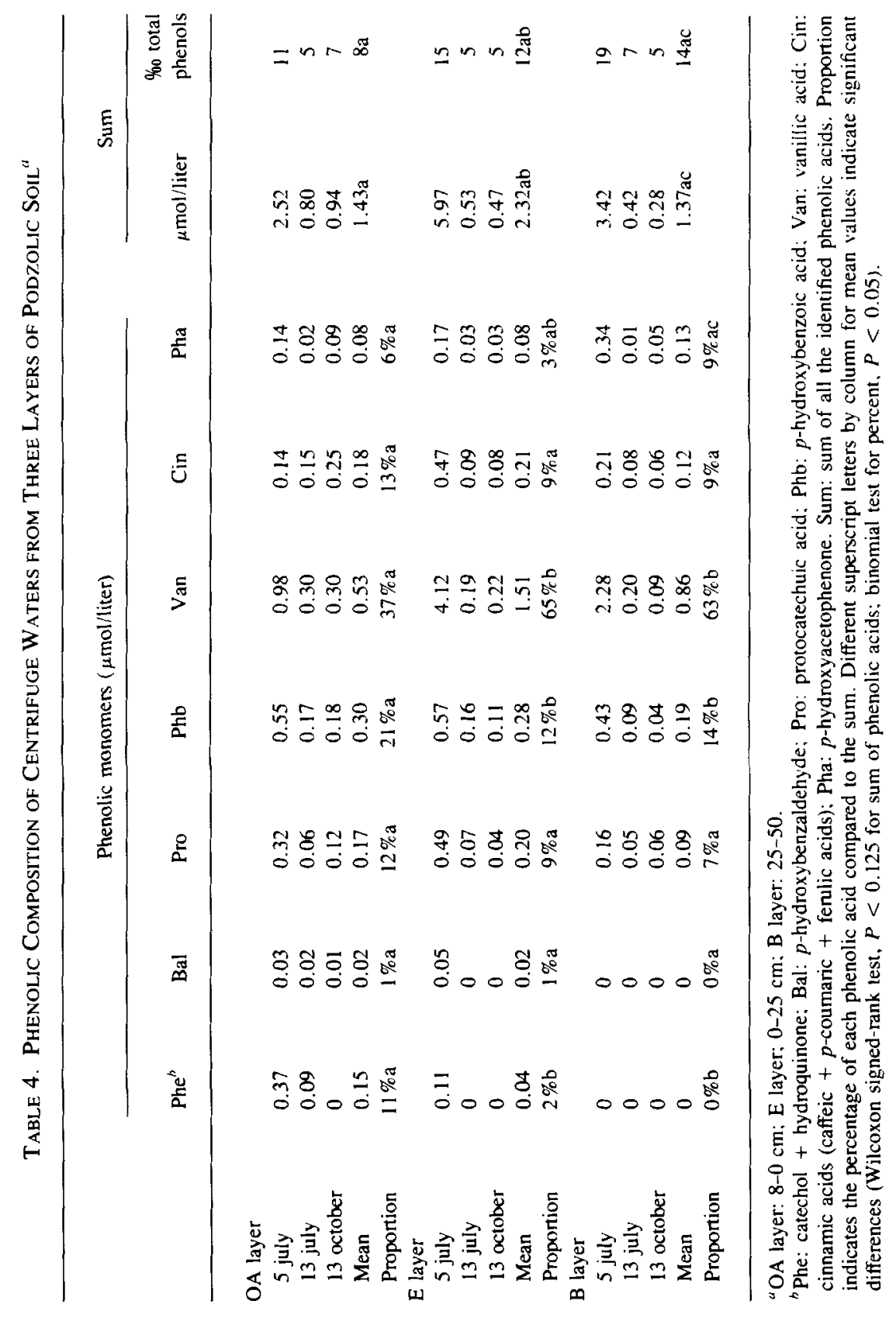


minor differences between $\mathrm{OA}$ and $\mathrm{E}$ solutions, but a significant decrease of the sum of all monomeric compounds between the $E$ and $B$ layers. The relative proportions of each phenolic acid identified in the soil solutions are similar for the three layers, with vanillic acid $>p$-hydroxybenzoic acid $\sim$ ferulic $+p$ coumaric acids $>$ protocatechuic acid $>p$-hydroxyacetophenone $>$ catechol + hydroquinone $>p$-hydroxybenzaldehyde as the general pattern. The contributions of simple phenols and aldehydes to phenolic monomers decreased with depth, and these compounds were not present in B layer solutions. Protocatechuic acid and cinnamic acids were relatively stable in all solutions, while increasing proportions of $p$-hydroxyacetophenone and of vanillic acid occurred with depth. The contribution of phenolic acids to the total phenolic fraction was low and essentially constant with depth, with a significant correlation between their sum and the total phenols $(r=0.93, N=9, P=0.001)$. The phenolic acids content of the earliest samples was higher than the others for vanillic acid.

Total phenol and phenolic monomer amounts were of the same order in spruce throughfalls and in soil solutions collected below the OA layers, while snow samples appear much less concentrated. $\mathrm{pH}$ and total phenols were negatively correlated, when comparisons of throughfalls, snow, and soil solutions data are analyzed together $(r=-0.74, N=22, P=0.001)$.

\section{DISCUSSION}

The phenolic patterns of the natural solutions sampled in the spruce stands show significant masses of numerous spruce metabolites and of some of their transformation products. For instance, spruce stems and needles release high quantities of tanning phenolics in throughfalls. Although no precise chemical identification has been attempted, it can be predicted that both proanthocyanidins found in needles (Gallet and Lebreton, 1995) and stilbenes present in bark (Hegnauer, 1966) will contribute to this fraction. The ecological impact of these polyphenols has been emphasized in living tissues through responses to pathogen attacks (Brignolas et al., 1995), but no studies on their extracellular and structural evolution (after tree death or after leaching outside) have been performed, especially in such acidic conditions. The great input of tannins close to the trunk could have major effects on the patterning of vegetation and microorganisms (Stöckli, 1991) in this area, through direct toxicity or by nitrogen (Schimel et al., 1996) and other elements, e.g., iron (Mila et al., 1996) immobilization. The concurrent slowing down of litter degradation would increase the organic matter accumulation, typical of such acidic coniferous system.

In the monomeric fraction, $p$-hydroxyacetophenone and vanillic acid appeared to be the most characteristic constituents of these natural solutions. 
The ubiquitous occurrence (in snow, leachates, and soil) of p-hydroxyacetophenone is a proof of its persistence and its relative stability in the forest system. Indeed, unlike vanillic acid or other widespread phenolic acids identified in these solutions, $p$-hydroxyacetophenone is a specific metabolite, only synthesized by spruce, being neither a degradation product nor a microorganism metabolite. To our knowledge, this is the first report of the occurrence in snow of an allelochemical that appears to have been leached from the decaying needles visible in the snow. The greater concentration of $p$-hydroxyacetophenone in snow in close contact with soil $(0-5 \mathrm{~cm})$ compared to the upper layers could be through capillary action from the humus solutions below. In soil solutions, $p$-hydroxyacetophenone constitutes a higher proportion of the phenolic monomers in the deepest soil layer (B), suggesting a lack of specific microorganisms capable of degrading it. The extracellular stability of this compound is probably of great significance in spruce ecology, because of its fungistatic properties (Osswald et al., 1987) and as the aglycone moiety of the picein compound that has been identified as an indicator of spruce die-back (Hoque, 1985; Richter and Wild, 1992).

Following germination, the roots of spruce seedlings are in contact with macroporous water from the soil surface layer. Throughfalls and OA solutions exhibited qualitative as well as quantitative differences in their phenolic patterns, indicating inputs and/or transformation of materials as soon as the throughfalls reach the litter layers. For instance, the high tanning capacity observed in the spruce throughfalls will interact both with litter components and with microorganisms. The evolution of these phenolic patterns in the deeper layers gave some information on the biological activity in the soil. Biodegradation or adsorption and precipitation processes are generally low in the organomineral layers, although mainly active in the B layer, as previously shown by Guggenberger and Zech (1994). Qualitative differences in the patterns of phenolic acids in the different layers show biotransformations as, for example simplification of cinnamic acids (like ferulic acid) to benzoic acids (like vanillic acid). The disappearance of catechol, and to a lesser extent protocatechuic acid, with depth can be explained. These compounds are readily degraded or further polymerised (Barz and Weltring, 1985). The prevalence of vanillic acid in capillary waters was the result of its continuous release from spruce lignin, which is characterized by high vanillyl phenols content (Ziegler et al., 1985). Although $p$-hydroxyacetophenone, and to a lesser extent vanillic acid, can be seen as strict indicators of spruce metabolism, an important source of the other phenolic acids, such as the cinnamic acids, could be understorey species with dense cover like Vaccinium myrtillus (Gallet and Lebreton, 1995).

It is often difficult to demonstrate convincingly the allelopathic activity of phenolic compounds. The problem is that the concentrations of putative allelochemical compounds, when measured in field experiments are often lower 
than the active concentrations displayed in greenhouse or in vitro experiments. For example, the inhibitory effect of $p$-hydroxyacetophenone on germination and primary growth of spruce seedlings has been established for concentrations of $10^{-4} \mathrm{M}$ (Gallet, 1994), but the lower concentrations of the natural solutions found in this study (about $10^{-6} \mathrm{M}$ in leachates, $10^{-7} \mathrm{M}$ in snow and soil solutions) have been shown to be active against mycorrhizal fungi respiration (Boufalis and Pellissier, 1994). Comparable situations have been observed with other plant phenolic acids, often described as allelochemicals, despite their weak quantities in soils. In our study, the three types of solutions-leachates, snow, and OA solutions-were collected at different times over a four-month period. The results enabled a comparison of their respective concentrations, indicating increasing amounts (for total phenols, and sum of monomeric compounds) from snow to throughfalls and soil solutions, associated with decreasing $\mathrm{pH}$. This is consistent with the conclusion that phenolic compounds could persist and accumulate in soil, but the polyphenols in leachates (c.g. tannins) probably have more of a complexing activity than the mixtures of polymerized molecules in the soil solutions. Indeed, phenolic monomers are only a minor fraction of the total phenolic fraction of forest soil solutions, determined as the "total phenols" using Folin-Ciocalteau reaction. Oligomers and soluble polymers (i.e., fulvic acids) of low molecular weight $(<1000)$ are known to be prevalent in soil solutions (Dawson et al., 1978), with as yet little detail available about their chemical structure, e.g., the number of aromatic rings. However, the influence of such compounds on plant growth has been shown (Dell'Agnola and Nardi, 1987; Vallini et al., 1993). Under field conditions, the aerial parts of the seedlings would be exposed from time to time to large amounts of $p$-hydroxyacetophenone and tannins, while the root system will be in permanent contact with a greater variety of phenolic monomers (at least 10 compounds) present in the macroporous and acidic waters of the organic layer.

Although certainly related to the interactive effects of climatic variations, soil status, and plant phenology, the observed temporal variability is difficult to explain because of the small number of replicates. Furthermore, it is possible that the variability is enhanced by the harsh conditions occurring at this altitude. Low-temperature, flooded conditions during the snowmelt period, and the brief growing period will all produce conditions unfavorable to degradation of the phenolic compounds (Dao, 1987), thereby producing peaks and troughs of phenolic fluxes throughout the spruce system.

The ubiquity, quantities, and activities of varjous spruce phenolic compounds seem compatible with their involvement in complex interactions occurring on forest floor, including direct allelopathic processes as well as nutrient immobilization. In all cases, a better knowledge of their field variability (spatial as well as temporal) might improve our understanding of their implications in forest dynamics. 
REFERENCES

AFES (Association Française pour L'Etune: du SOL). 1992. Référentiel pédologique: Les principaux sols d'Europe. INRA Publishers, Paris.

ARTHUR, M. A., and FAHEY, T. J. 1993. Throughfall chemistry in an Engelmatnn spruce-subalpine fir forest in north central Colorado. Can. J. For. Res. 23:738-742.

BARz. W., and WETTRING, K. M. 1985. Biodegradation of aromatic extractives of wood. pp. 607662 in T. Higuchi (ed.). Biosynthesis and Biodegradation of Wood Components. Academic Press, New York.

Bernifr, N., Ponge, J. F., and Andre, J. 1993. Comparative study of soil organic layers in two bilberry-spruce forest stands (Vaccinio-Piceetea). Relation to forest dynamics. Gocolerma 59:89-108.

Boufalis, A. and Pellissir:R, F. 1994. Allelopathic effects of phenolic mixtures on respiration of two spruce mycorrhizal fungi. J. Chem. Ecol. 20:2283-2289.

Brignolas, F., Lacroix, B., lieutilk, F., Sauvaris, D., Drouit, A., Claudot, A. C., Yart, A., Berryman, A. A., and Christiansen, E. 1995. Induced responses in phenolic netabolism in two Norway spruce clones after wounding and inoculations with Ophiosioma polonicum, a bark bectle-associated tungus. Plam Physiol. 109:821-827.

Dalton, B, R., Ste.rl.jng, B. W.. and Bi.um, U, 1987. Plant phenolic acids in soil: A comparison of extract procedures. Soil Sci. Soc. Am. J. 51:1515-1521.

D^๐, T. H. 1987. Sorption and mineralization of plant phenolic acids in soil, pp. 358-370 in G. R. Waller (ed.). Allelochenicals: Role in Agriculture and Forestry. American Chemical Society, Symposium Series, Washington, D.C. 330.

Dawson, H. J., Ugolini, F. C., Hrurriorord, B. F., and Zachars, J. 1978. Roje of soluble organics in the soil processes of a podzol, Central Cascades, Washington. Soil Sci. 126:290-296.

DELL A(INO).A, G., and NARDI, S. 1987. Homone-like effect and enhanced nitrate uptake induced by depolycondensed humic tractions obtained from Allohohophara rosea and Allolobophara caliginosa faeces. Biol. Forril. Sorils 4:115-118.

Fifld, J. A., and Letringa, G. 1992. Toxicity of tannins compounds to microorganisms, pp. 673692 in R. W. Hemingway and P. E. Laks (eds.). Plant Polyphenols. Plenum Press, New York.

GALLeT. C. 1994. Allelopathic potential in bilberry-spruce forests: Influence of phenolic compounds on spruce seedlings. J. Chem. Ecol. 20;1009-1024.

Gall.t, C., and Lebreton, P. 1995. Evolution of phenolic patterns in plants and associated litters and humus of a mountain forest ecosystem. Soil Biol. Biochem. 27:157-165.

Girislfi, R., and Lundstrom, U. 1993. Soil solution chemistry: Effects of bulking samples. Soil Sci. Soc. Am. J. 57:1283-1288.

GUGgenbergir, G. and Zter, W. 1994. Composition and dynamics of dissolved carbohydrates and lignin degradation products in two coniferous forests, N.E. Bavaria, Germany. Soil Biol. Biochem. 26:19-27.

Hitinaule, R. 1966. Chemotaxonomie der Planzen. Birkauser, Basel.

Hoqur, E. 1985. Norway-spruce dieback: Occurrence, isolation and biological activity of p-hydroxyacetophenone and $p$-hydroxyacetophenone- $O$-glucoside and their possible roles during stress phenomena. Eur. J. For. Pathol. 15:129-145.

INDERJIT, and MALLIK, A. U. 1996. Growth and physiological responses of black spruce (Piced mariana) to sites dominated by Ledum groenlandicum. J. Chem. Ecol. 22:575-585.

KFLL.ER, C. 1995. Application of centrifuging to heavy metal studies in soil solutions. Commun. Soil Sci. Plant Anal. 26:1621-1636.

KII., B., and YIM, Y. 1983. Allelopathic effects of Pints densiffora on undergrowth of red pine forest. J. Chem. Ecol. 9:135-1151. 
MaRIGO, G. 1973. Sur une méthode de fractionnement et d'estimation des composés phénoliques chez les végétaux. Analusis 2:106-110.

MILA, I., SCALBERT, A., and EXPERT, D. 1996. Iron withholding by plant polyphenols and resistance to pathogens and rots. Phytochemistry 42:1551-1555.

Northup, R. R., YU, Z., Dahlgren, R. A., and VoGt, K. A. 1995. Polyphenol control of nitrogen release from pine litter. Nature 377:227-229.

Odén, P. R., Brandtberg, P., Andersson, R., Gref, R., Zackrisson, O., and Nilsson, M. C. 1992. Isolation and characterization of a germination inhibitor from leaves of Empetrum hermaphroditum Hagerup. Scand. J. For. Res. 7:497-502.

Osswald, W. F., Zifboll, S., Schutz, W., Firl, J., and Elstner. E. F. 1987, p-hydroxyacetophenone a fungitoxic compound in spruce needles. J. Plam Dis. Protect. 94:572-577.

Parker, G. G. 1983. Throughfall and stemflow in the forest nutrient cycle. Adv. Ecol. Res. 13:58133.

Pellissier, F. 1993. Effect of phenolic compounds in humus on the natural regeneration of spruce. Phytochemistry 36:865-867.

Pohlman, A. A., and MCColL, J. G. 1988. Soluble organics from forest litter and their role in metal dissolution. Soil Sci. Soc. Am. J. 52:265-271.

RICHTER, C. M., and WILD, A., 1992. Phenolic compounds in needles of Norway spruce trees in relation to novel forest decline. I. Studies on trees from a site in the northern Black Forest. Biochem. Physiol. Pflanzen 188:305-320.

Schimel, J. P., Van Clevf, K., Cates, R. G., Clausen, T. P., and Reichardt, P. B. 1996. Effects of balsam poplar (Populus balsamifera) tannins and low molecular weight phenolics on microbial activity in taiga foodplain soil: implications for changes in $\mathrm{N}$ cycling during succession. Can. J. Bot. 74:84-90.

Schultz, J. C., Baldwin, I. T., and Nothnagli, P. J. 1981. Hemoglobin as a binding substrate in the quantitative analysis of plant tannins. J. Agric. Food Chem. 29:823-826.

STöckL, H. 1991. Influence of stemflow upon the decomposing system in two beech stands. Rev. Ecol. Biol. Sols 28:265-286.

Sugal, S. F., and SChimfl, J. 1993. Decomposition and biomass incorporation of ${ }^{14} \mathrm{C}$-labeled glucose and phenolics in taiga forest floor: Effect of substrate quality, successional state, and season. Soil Biol. Biochem. 25:1379-1389.

Vallini, G., Pfra, A., Avio, L., Valdrigh, M., and Giovanetri, M. 1993. Influence of humic acids on laurel growth, associated rhizopheric microorganisms, and mycorrhizal fungi. Biol. Fertil. Soils 16:1-4.

VanCE, G. F., Boyd, S. A., and Mokma, D. L. 1985. Extraction of phenolic compounds from a spodosol profile: An evaluation of three extractants. Soil Sci. 140:412-420.

VANCE, G. F., Mokma, D. L., and Boyd, S. A., 1986. Phenolic compounds in soils of hydrosequences and developmental sequences of spodosols. Soil Sc. Soc. Am. J. 50:992-996.

Whitehead, D. C., DibB, H., and Hartley, R. D. 1983. Bound phenolic compounds in water extracts of soils, plant roots and leaf litter. Soil Biol. Biochem. 15:133-136.

ZabowSKI, D., and UgolinI, F. C. 1990. Lysimeter and centrifuge soil solutions: Seasonal differences between methods. Soil Sci. Soc. Am. J. 54:1130-1135.

ZIEGLER, F., KöGFL, I., and ZFCH, W. 1986. Alteration of gymnosperm and angiosperm lignin during decomposition in forest humus layers. Z. Planzenernaehr. Bodenk. 149:323-331. 